\title{
Buckling of Compressed-Bent RC Elements of Frame-Bracing Structural System at "Unknown" Accidental Impacts
}

\author{
Natalia Fedorova ${ }^{1}$, Sergey Savin ${ }^{2, *}$ and Vladislav Kovalev $^{2}$ \\ ${ }^{1}$ Moscow State University of Civil Engineering, Yaroslavskoe shosse, 26, Moscow, 129337, Russia \\ ${ }^{2}$ South-West State University, 50 let Oktyabrya street, 94, Kursk, 305040, Russia
}

\begin{abstract}
The paper presents the results of studies of the buckling of the bearing elements of the new structural system, which consists of reinforced concrete precast-monolithic panels-frames produced industrially under a special accidental impact caused by a sudden column removal from the building frame. It is established that under special accidental impact caused by a sudden column removal from RC precast-monolithic structural system consists of industrial panel-frame elements, the reason of the fracture spreading within and outside local damage (fracture) zone may be the buckling of compressed-bent elements.
\end{abstract}

\section{Introduction}

Building constructions of residential, public and industrial buildings and structures during their lifetime may be subjected to extreme or, following the terminology adopted in the new regulatory document [1], "special accidental impacts" associated with terrorist attacks, gas explosions, vehicle impact, sudden stoppage of the technological process, high temperatures, etc. The collapse of such objects as Ronan Point (London, 1968), Sampoong shopping centre (Seoul, 1995), World Trade Centre (New York, 2001), Transvaal Park (Moscow, 2004), Rana Plaza (Savar, 2013) and others, shows that the local destruction of a construction or it element arising under extreme impacts can cause progressive collapse of the entire structural system and, as a consequence, a large number of victims.

Due to the wide range of special accidental impacts and the inability to completely eliminate the risk of their occurrence, the building regulations [1-8] almost all over the world adopt a situational approach as the main calculating method of protection against progressive collapse. According to this approach, the calculation is carried out on the "unknown" impact, the result of which is the removal of a bearing element from the structural system of the building or structure. As such element it is most often selected column or section of the wall. A significant number of publications in the scientific literature on the problem of resistance to progressive collapse of reinforced concrete frames of buildings and structures devoted to the study of dynamic load increment, deforming and resistance to fracture of coatings and floors [9-11], nodes or building frames [12-18]. The

\footnotetext{
Corresponding author: suwin@yandex.ru
} 
quasi-static method [19] or dynamic approach [20, 21], as well as the limit equilibrium method [22] are usually used for numerical simulation of construction resistance under the special accidental impacts. At the same time, the criteria for assessing the resistance of building structures to destruction in post critical stage caused by the "unknown" special accidental impact in the mentioned works are the parameters associated with the strength of structural elements. However, a number of factors, such as a decrease in the size of the cross sections due to the more wide use of concrete compressive strength classes C60 and above, a decrease in the value of the deformation modulus caused by the phenomena of primary and secondary creep [23], corrosion [24 - 27] or thermal damage [28], leads to the fact that the cause of the spread of damage within and outside the local damage zone can be the loss of stability of compressed and compressed-bent bearing elements of the structural system [29-30]. In this regard, the paper presents the results of numerical investigations of the buckling of the bearing elements of the new structural system, which consists of reinforced concrete precast-monolithic panels-frames produced industrially under a special accidental impact caused by a sudden column removal from the building frame.

\section{Models and Methods}

The object of the investigation is a multi-storey building of mass construction with a precast-monolithic reinforced concrete building frame consisting of panels-frames of industrial production and prefabricated hollow slabs which are united in a spatial structural system by filling the space in the upper parts of the girders of panels-frames and interplate joints by monolithic concrete (fig. 1).

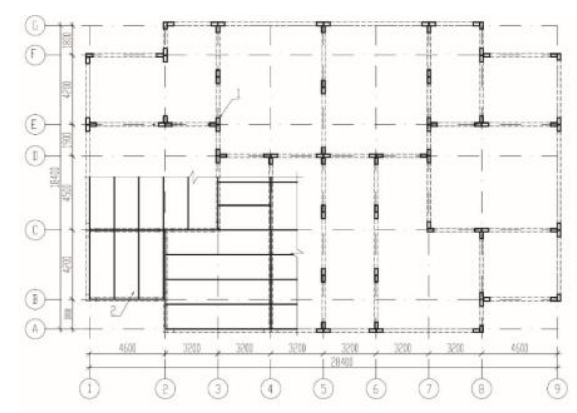

(a)

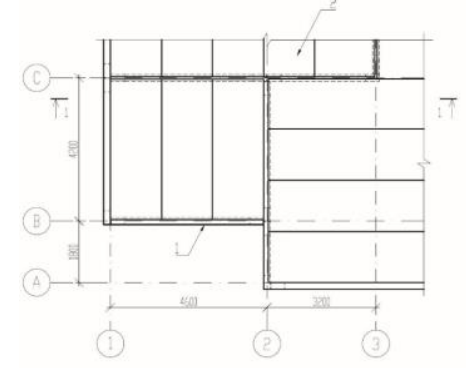

(c)

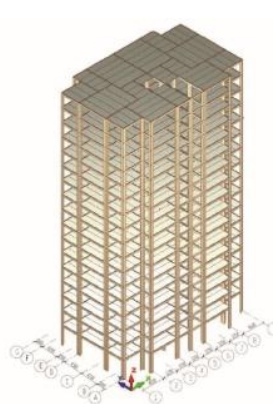

(b)

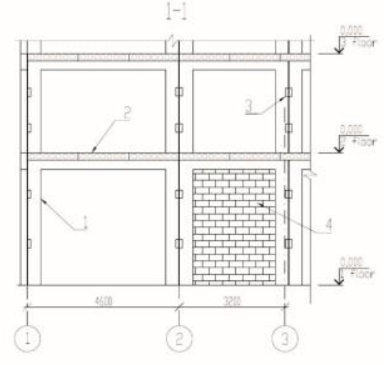

(d)

Fig. 1. The building frame consisting of RC industrial panel-frame elements: a) plan;

b) general view of the structural system; c) layout scheme slabs;

d) section 1-1. 1 - industrial panel-frame element; 2 - prefabricated hollow slab;

3 - connecting element; 4 - masonry filling the opening in the panel-frame.

The elements of the mentioned reinforced concrete frame high-rise building made of the panel-frame industrial constructions were simulated in the following way (figure 2, a): 
columns and girders of panel-frame constructions were modelled by spatial universal rod finite elements; details that connect the columns of neighbour panels through the height (element 2 in fig. 1 (b)), where modelled by coupling degree of freedom along the X, Y, Z axes in the corresponding nodes of adjacent panels; hollow slabs were modelled by plate finite elements of equivalent stiffness (by deformation criterion). Node restraints on the contour of the floor and coating slab were modelled as hinges.

In accordance with [2], using the presented first and second level (after the removal of the first floor column) calculation models the numerical studies of the redistribution of power flows in the considered structural system after the special accidental impact were carried out. At the same time, an advanced analysis of the individual fragments of the building frame was performed by the method of substructures. For this purpose, the calculation schemes of the second and third levels were used [30].

\section{Results and discussion}

According to the results of the analysis of the spatial RC building frame model subjected the action of the design combination of loads (fig. 2 (b)) the fragment of flat building frame including the most loaded columns of the first floor was chosen for an advanced analysis of the power resistance to progressive collapse of the calculation model of the first level (fig. 3).

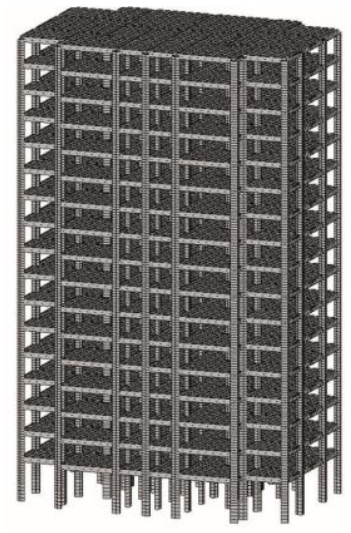

(a)

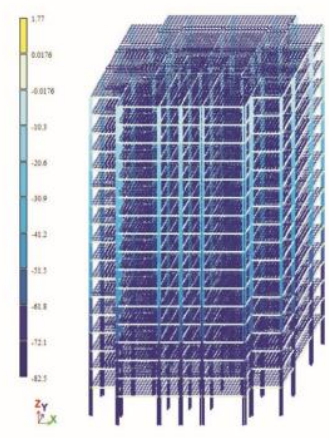

(b)

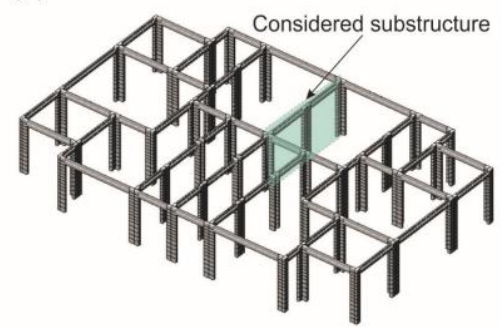

(c)

Fig. 2. Finite element model of the first level (a),

mosaic plot of forces in the elements at the most unfortunate design combination of loads (b), finite element model of the first floor with a dedicated substructure (c)

As an "unknown" impact the removal of the outer column from the flat building frame was considered as it is shown in fig. 3 (a). The dynamic effect arising in this case was 
modelled by applying a quasi-static approach when the concentrated load, the value of which equals to the force in this column at the design combination of loads at the stage of normal operation, should be attached in opposite direction instead the destroyed column to the secondary calculation scheme as it is shown in fig. 3 (b). The structural elements of the flat frame in the third level design schemes were modelled by finite elements taking into account the physical nonlinearity.

Adopted cross-section of the columns and girders in the design schemes of the third level are shown in fig. 3 (c) and fig. 3 (d) respectively. Exponential stress-strain dependences according to Eurocode Design of concrete structures EN1992-1-1 were applied to simulate the physical nonlinearity of concrete (C60) and reinforcement (A500).

The forces in the substructure of the flat frame fragment at the design combination of loads are shown in fig. 4.

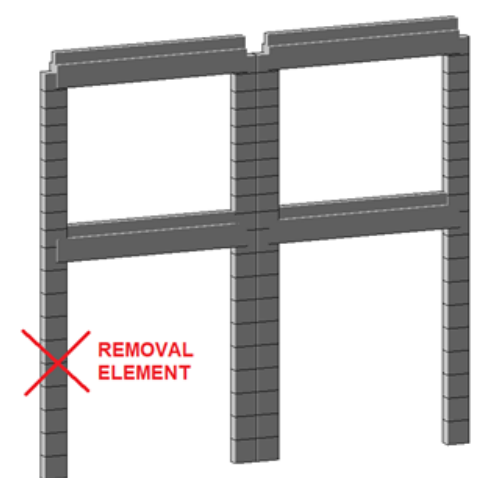

(a)

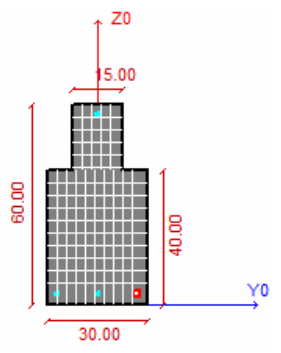

(c)

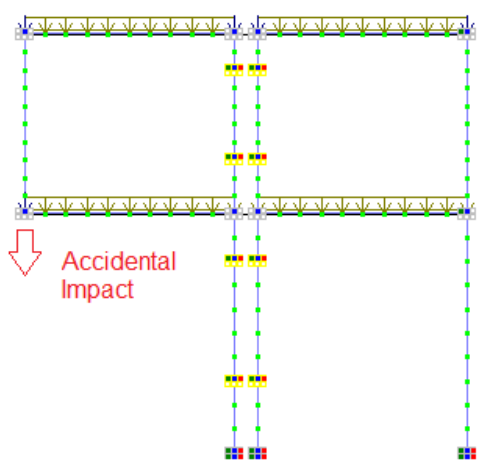

(b)

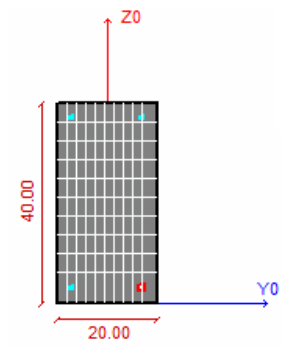

(d)

Fig. 3. Finite element model of the flat fragment of the RC building frame situated in the zone of possible local failure caused by the removal of the column (a), the secondary design scheme (b), cross sections of a girder (c) and a column (d) in the design schemes of the third level (for sections) 


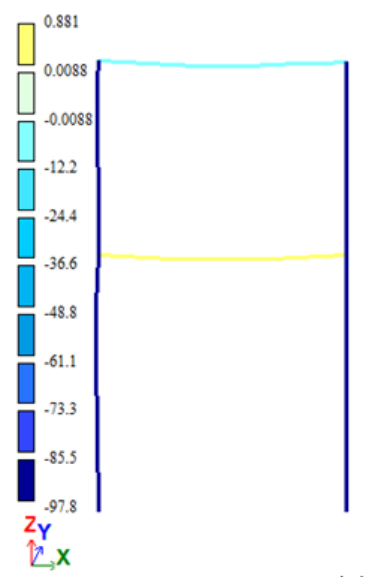

(a)

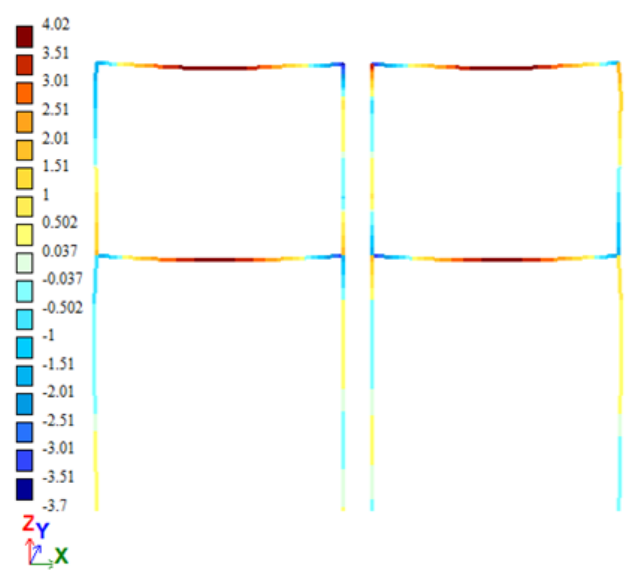

(b)

Fig. 4. Axial forces $\mathrm{N}\left(10^{-1} \mathrm{kN}\right)(\mathrm{a})$ and moments $\mathrm{My}_{\mathrm{y}}\left(10^{-1} \mathrm{kN} * \mathrm{~m}\right)(\mathrm{b})$ at the design combination of loads.

When axial forces in the columns of the fragment "A" of the panel-frame element shown in figure 5 achieve values of $\mathrm{N}=\mathrm{N}_{\mathrm{cr}}=1550 \mathrm{kN}$ the considered columns change it form of stable equilibrium (buckling). It leads to destructions of the elements noted in fig. 5 (b).

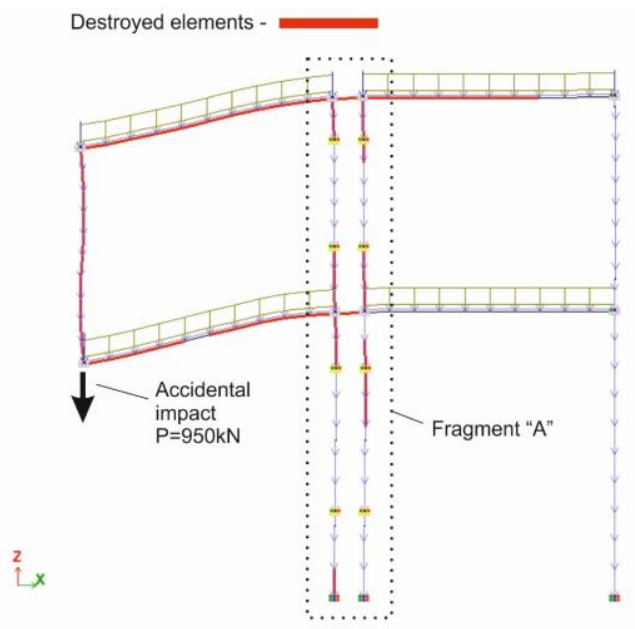

(a)

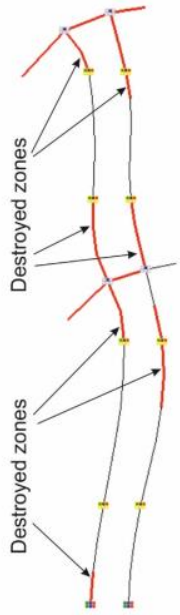

(b)

Fig. 5. The results of the numerical analysis of the considered fragment of structural system power resistance to progressive collapse when the outer column of the first floor is removed (a), fragment "A": the buckling mode at $\mathrm{N}_{\mathrm{cr}}=1550 \mathrm{kN}$

As a variant of protection of the considered building frame against progressive collapse, it is proposed to accept additional panel-frame constructions installed in the orthogonal direction, the column of which are connected with the considered panels through the height at least in two places (fig. 1). 


\section{Conclusions}

It is established that under special accidental impact caused by a sudden column removal from RC precast-monolithic structural system consists of industrial panel-frame elements, the reason of the fracture spreading within and outside local damage (fracture) zone may be the buckling of compressed-bent elements.

For a more accurate assessment of the resistance by the stability criterion to progressive collapse of RC structural systems at post-critical stages caused by the sudden load-bearing element removal, it is necessary to conduct a series of experimental studies of such constructions to identify the real stress-strain-time diagram for different modes of dynamic loading of statically preloaded and long term deformed RC elements.

\section{References}

1. Building Code of RF SP 296.1325800.2017 Building and Structures. Accidental impacts (2017)

2. Building Code of RF SP 385.1325800.2018 Protection of buildings and structures against progressive collapse. Design code. Basic statements (2018)

3. EN 1991-1-7-2006 Eurocode 1: Actions on structures - part 1-7: general actions accidental actions.

4. UFC 4-023-03 (Including Change 3, 2016) Unified facilities criteria. Design of buildings to resist progressive collapse

5. The building regulations 2010 - structure: approved document A. UK: HM Government (2010)

6. National Research Council of Canada. National building code of Canada. Canadian Commission on Building and Fire Codes (1995)

7. Australian Building Codes Board (ABCB). National construction code (NCC). Council of Australian Governments (2016)

8. China Association for Engineering Construction Standardization (CECS). Code for anticollapse design of building structures, CECS 392: 2014. Beijing (China) (2014)

9. Jose M. Adama, Fulvio Parisi, Juan Sagaseta, Xinzheng Lu, Engineering Structures, 173, 122, (2018)

10. Jian Weng, Chi King Lee, Kang Hai Tan, Namyo Salim Lim, Engineering Structures, 149, 147, (2017)

11. V.I. Travush, N.V. Fedorova, Magazine of Civil Engineering, 81, 73, (2018)

12. Setareh Amiri, Hamed Saffari, Javad Mashhadi, Engineering Failure Analysis, 84, 300, (2018)

13. J. Weng, K.H. Tan, C.K. Lee, Engineering Structures, 151, 136, (2017)

14. Emanuele Brunesi, Fulvio Parisi, Engineering Structures, 152, 579, (2017)

15. Elisa Livingston, Mehrdad Sasani, Marlon Bazan, Serkan Sagiroglu, Engineering Structures, 95, 61, (2015)

16. Y.A. Al-Salloum, H. Abbas, T.H. Almusallam, T. Ngo, P. Mendis, J. of King Saud University - Engineering Sciences, 29, 313, (2017)

17. Pascal Forquin, Wen Chen, Construction and Building Materials, 152, 1068, (2017)

18. Peng Feng, Hanlin Qiang, Weihong Qin, Meng Gao, Engineering Structures, 147, 752, (2017)

19. V.I. Kolchunov, N.V. Klyueva, N.B. Androsova, A.S. Bukhtiyarova, Survivability of buildings and structures at accidental impacts (Publishing ASV, Moscow, 2014)

20. A.M. Belostotsky, Int. J. for Computational Civil and Structural Engineering, 8, 54, (2012)

21. Javad Mashhadi, Hamed Saffari, J. of Constructional Steel Research, 138, 72, (2017) 
22. S.A. Zenin, R.S. Sharipov, O.V. Kudinov, G.I. Shapiro and A.A. Gasanov, ACADEMIA. Architecture and construction, 2, 7 (2016)

23. R.S. Sanzharovsky, M.M. Manchenko, Structural Mechanics of Engineering Constructions and Buildings, 2, 33, (2015)

24. V.I. Kolchunov, S.Yu. Savin, Magazine of Civil Engineering, 80, 73, (2018)

25. N.V. Fedorova, S.Yu. Savin, IOP Conference Series: Materials Science and Engineering, 365, 052018, (2018)

26. V.M. Bondarenko, N.V. Klyueva, News of higher educational institutions. Construction, 1, 4, (2008)

27. V.P. Selyaev, P.V. Selyaev, M.F. Alimov, E.V. Sorokin, Stroitel'stvo i Reconstruktsiya, 6, 49, (2017)

28. V.S. Fedorov, V.E. Levitsky, I.A. Solovyev, Stroitel'stvo i Reconstruktsiya, 61, 47, (2015)

29. V.I. Kolchunov, N.O. Prasolov, A.S. Bukhtiyarova, Promyshlennoe i grazhdanskoe stroitel'stvo, 12, 42, (2013)

30. S.Yu. Savin, V.I. Kolchunov, S.G. Emelianov, IOP Conference Series: Materials Science and Engineering, 456, 012089, (2018) 